\title{
Kinetic Study Of Structural Hardening Mechanisms Of PbCdBiSn And PbCdBiMg Alloys For The New Generation Of Battery Grids
}

\author{
Soukaina SAISSI ${ }^{1, a^{*}}$, Elmadani SAAD ${ }^{1, b}$
}

1: University Hassan 1 FST Settat, Laboratory of Physical chemistry of Materials and Processes (MPCP), SETTAT, MOROCCO.

as.saissi@uhp.ac.ma, bsaadelmadani73@gmail.com

Keywords: alloy, battery grids, structural hardening, aging, over-aging.

\begin{abstract}
The study of the return to equilibrium state of $\mathrm{PbCdBiSn}$ and $\mathrm{PbCdBiMg}$ alloys has been studied. Indeed, two structural states were considered: raw casting alloy and rehomogenized alloy. The experimental temperatures are $20^{\circ} \mathrm{C}$ and $80^{\circ} \mathrm{C}$. The latter temperature was selected because it corresponds to the temperature of ripening of battery grids and extreme temperature for operating a battery. We studied the kinetics of $\mathrm{Pb} 2 \% \mathrm{Cd} 1 \% \mathrm{Bi} 0,5 \% \mathrm{Sn}$ and $\mathrm{Pb} 2 \% \mathrm{Cd} 1 \% \mathrm{Bi} 2 \% \mathrm{Mg}$. The activation energy of the alloy without tin remains less than the one with tin and approximate to that with Magnesium.
\end{abstract}

\section{I- INTRODUCTION:}

The discontinuous transformation and the hardening continuous reaction are the structural competitive mechanisms of quaternary alloys $\mathrm{PbCdBiSn}$ and $\mathrm{PbCdBiMg}$ during aging, while overaging is characterized by softening discontinuous precipitation which precipitate is cadmium.

The kinetics of softening discontinuous precipitation of $\mathrm{Pb} 2 \% \mathrm{Cd} 1 \% \mathrm{Bi} 0,5 \% \mathrm{Sn}$ and $\mathrm{Pb} 2 \% \mathrm{Cd} 1 \% \mathrm{Bi} 2 \% \mathrm{Mg}$ alloys which characterizes the over ageing was jointly investigated by hardness measurements.

The heat treatments were carried out at temperatures $20^{\circ} \mathrm{C}$ and $80{ }^{\circ} \mathrm{C}$ for times varying from 110 min to 6 months at $20{ }^{\circ} \mathrm{C}$ and from 80 min to 6 months at $80{ }^{\circ} \mathrm{C}$ for the alloy $\mathrm{Pb} 2 \% \mathrm{Cd} 1 \% \mathrm{Bi} 0,5 \%$ $\mathrm{Sn}$, and during the time ranging from $154 \mathrm{~min}$ to 6 months at $20^{\circ} \mathrm{C}$ and $108 \mathrm{~min}$ to 6 months at 80 ${ }^{\circ} \mathrm{C}$ for the alloy $\mathrm{Pb} 2 \% \mathrm{Cd} 1 \% \mathrm{Bi} 2 \% \mathrm{Mg}$. And those applying the $\mathrm{x}$ Johnson-Mehl Avrami law and Burke's method [2].We are interested in the kinetic study on over-aging to compare the activation energy of these alloys with the activation energy of $\mathrm{Pb} 2 \% \mathrm{Cd} 1 \% \mathrm{Bi}$ already studied [1].

\section{II- METHODS AND EQUATIONS:}

\section{II.1. Degree of advancement of the reaction}

The degree of progress $\mathrm{x}$ of the reaction is given by the relation (Eq.1):

$$
x=\frac{H V(t)-H V(0)}{H V(\infty)-H V(0)}
$$

With:

\begin{tabular}{|c|c|c|}
\hline Parameter & Aging & Over-aging \\
\hline $\mathrm{HV}(\mathrm{t})$ & Hardness at time $(\mathrm{t})$ & Hardness at time $(\mathrm{t})$ \\
\hline $\mathrm{HV}(0)$ & $\begin{array}{c}\text { The initial hardness of hardening } \\
\text { transformation }\end{array}$ & $\begin{array}{c}\text { The initial hardness of softening } \\
\text { transformation }\end{array}$ \\
\hline $\mathrm{HV}(\infty)$ & $\begin{array}{c}\text { The final hardness of hardening } \\
\text { transformation }\end{array}$ & $\begin{array}{c}\text { The final hardness of softening } \\
\text { transformation }\end{array}$ \\
\hline
\end{tabular}




\section{II.2. Application of Johnson and Mehl-Avrami equation:}

\section{II.2.1. Generality}

The speed at which the isothermal transformation takes place is described by a law of the formula (Eq.2):

$$
x=f(t)
$$

Where $\mathrm{x}$ is the transformed fraction at time $\mathrm{t}$ and $x=f(t)$ is a function of time.

Several mathematical models have been proposed in the literature for connecting the speed of germination and growth with speed of transformation. Of all the possible relationships presented, the two most general forms we note:

- The Johnson and Mehl avrami equation;

- The Austin and Rickett equation.

These have been used many times, even for discontinuous transformations. Jenkel and Hammes [3] have shown; for example; that the discontinuous precipitation can be described by the equation of Johnson-Mehl-Avrami [2].

\section{II.2.2. Johnson and Mehl-Avrami equation}

A large number of reactions following a nucleation-growth process have a speed of the form (Eq.3):

$$
V=\frac{d x}{d t}=n k^{n} t^{n-1}(1-x)
$$

(1-x) reflects interference in growth and the term $n k^{n} t^{n-1}$ describes the rate law in the absence of mutual interference.

The integration of this relation led to the well-known equation of Johnson-Mehl-Avrami (Eq.4):

Or again in the form (Eq.5):

$$
x=1-\exp -(k t)^{n}
$$

$$
\log \log \left(\frac{1}{1-x}\right)=n \log k+n \log t
$$

$\mathbf{n}$ is a dimensionless whose value is independent of temperature, but dependent on the germination-growth process.

The coefficient $\mathbf{k}$ varies with the temperature and the dimension $\mathbf{t}^{\mathbf{1}}$.

The exponent $\mathbf{n}$ and the constant $\mathbf{k}$ are parameters that allow an accurate description of the kinetics of the isothermal reaction when it obeys to the equation of Johnson Mehl-Avrami. When the time is plotted on a logarithmic scale, the shape of the curve $x=f(t)$ is determined by the only exponent $\mathbf{n}$. The coefficient $\mathbf{k}$ fixe the intercept.

\section{III- DETERMINATION OF THE APPARENT ACTIVATION ENERGY:}

The apparent activation energy can be calculated from the variations of the coefficient $\mathbf{k}$ as a function of temperature. Indeed, in the case where it has an immediate saturation of the sites, the germination rate becomes zero and the speed of the front obeys to the equation (Eq.6):

$$
k=k_{0} \exp \left(-\frac{Q}{R T}\right)
$$

This is none other than the Arrhenius equation, with:

$\mathrm{K}_{0}$ : rate constant

Q: Activation energy relating to the progress of the reaction front.

$\mathrm{T}$ : The absolute temperature expressed in Kelvin degrees.

$\mathrm{R}$ : Universal constant of perfect gases $\mathrm{R}=8,32 \mathrm{~J} \cdot \mathrm{mol}^{-1} \cdot \mathrm{K}^{-1}$ 
However, it should be noted that this expression implicitly assumes that the total number of formed germs is independent of temperature. This expression can reach the value of the activation energy on the proposed kinetic regime through the linearized logarithmic representation in (Eq.7):

$$
\log \left(\frac{k_{1}}{k_{2}}\right)=-\frac{Q}{R}\left(\frac{1}{T_{1}}-\frac{1}{T_{2}}\right)
$$

\section{IV- KINETIC STUDY OF THE ALLOY Pb2\%Cd1\%Bi0, 5\%Sn}

\section{IV.1. degree of advancement of the reaction:}

Figure (fig.2) shows changes in the degree of advancement $\mathrm{x}$ of the transformation as a function of $\ln (\mathrm{t})$ for different temperatures $20^{\circ} \mathrm{C}$ and $80{ }^{\circ} \mathrm{C}$. We obtain sigmoidal curves, elongated along the axis of time. The variations of degree of advancement at temperatures $20^{\circ} \mathrm{C}$ and $80^{\circ} \mathrm{C}$ are deduced from hardness measurements according to over-aging as shown in figure (fig.1) [4].

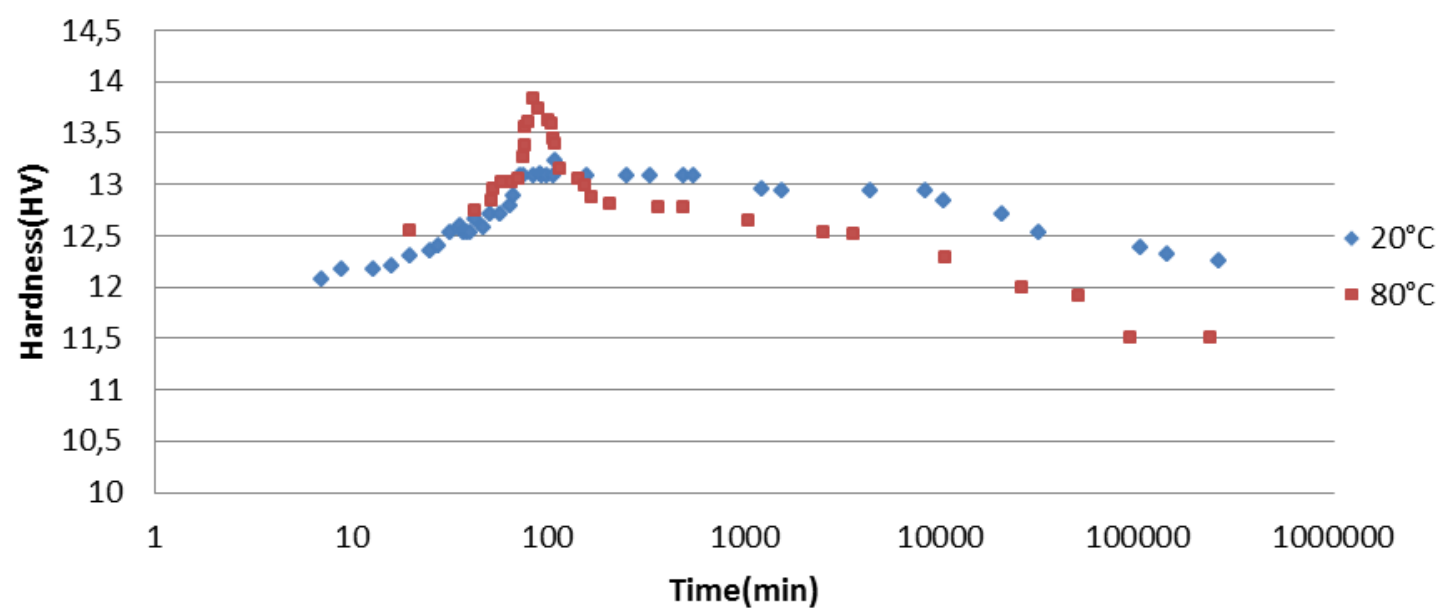

Fig.1. Evolution of the hardness of as cast alloy $\mathrm{Pb2} \% \mathrm{Cd} 1 \% \mathrm{Bi0}, 5 \% \mathrm{Sn}$ at temperatures $20^{\circ} \mathrm{C}$ and $80^{\circ} \mathrm{C}$ as a function of time.

We will take the maximum value of the curves of the evolution of the hardness versus time of Figure (fig.1), so $H V(0)=13,23 H V$ the final value of hardness for over-aging is reached since the last 6 month which is $H V(m)=12,259 H V$. The curves in Figure (fig.2), which are representative of the evolution of the discontinuous transformation, are deducted from hardness tests of Figure (fig.1) performed on raw casting samples maintained at $20^{\circ} \mathrm{C}$ and $80{ }^{\circ} \mathrm{C}$.

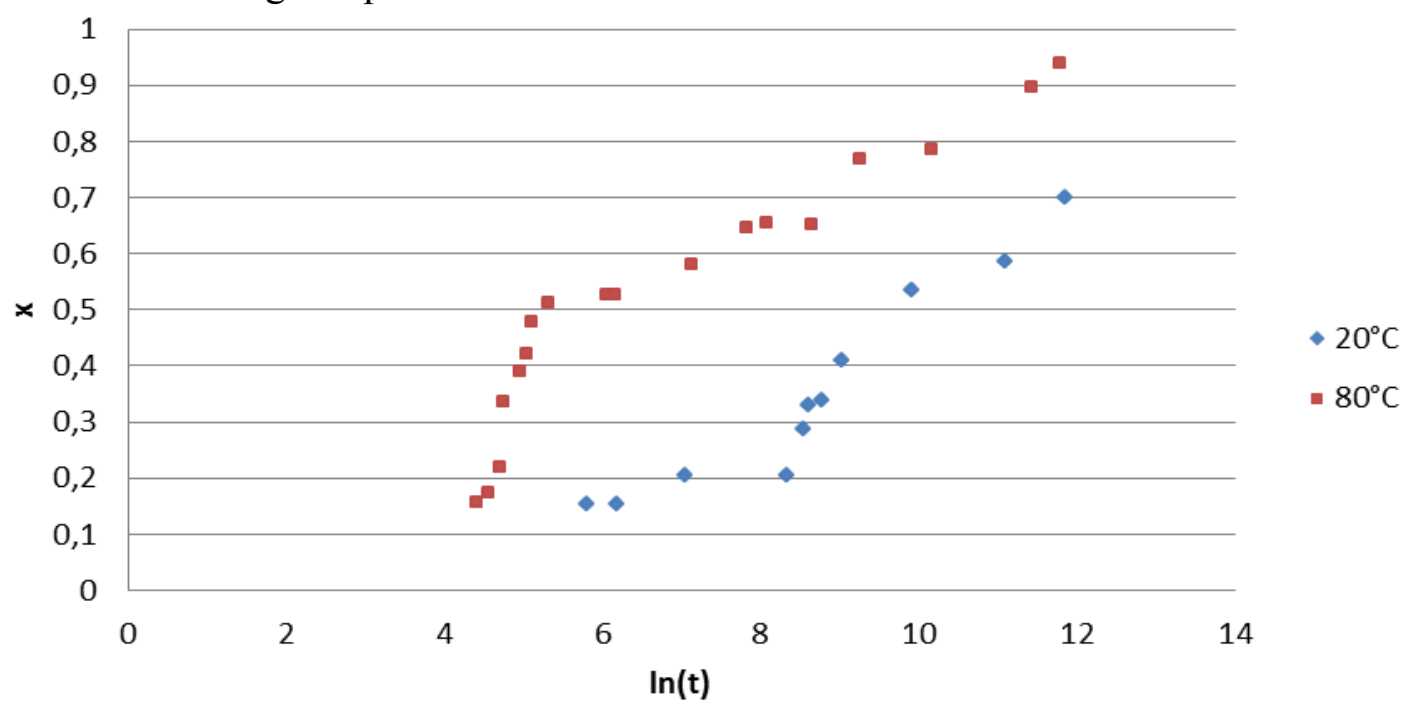

Fig.2. Pb2\%Cd1\%Bi0,5\%Sn alloy. Transformed semi logarithmic of the curves of hardness tests at the temperatures $20^{\circ} \mathrm{C}$ and $80^{\circ} \mathrm{C}$ for softening discontinuous precipitation of the raw casting alloy tempered in water. 


\section{IV.2. Application of Johnson and Mehl-Avrami equation}

Figure (fig.3) represents variations of $\log \log \left(\frac{1}{1-x}\right)$ as function of $\log (\mathrm{t}-\tau)$.

The start times $\tau$ of this transformation are respectively $110 \mathrm{~min}$ and $80 \mathrm{~min}$ for the temperatures $20^{\circ} \mathrm{C}$ and $80^{\circ} \mathrm{C}$. This figure shows that the points are placed on straight lines. The progress of this reaction is in conformity with Johnson and Mehl-Avrami equation [2].

Table 1 gives the values of the exponent $n$ calculated from the slope of the lines of Figure (fig.3) and the rate constants $\mathrm{k}$ for the different temperatures. The value of $\mathrm{n}$ is close to 0.27 for both temperatures.

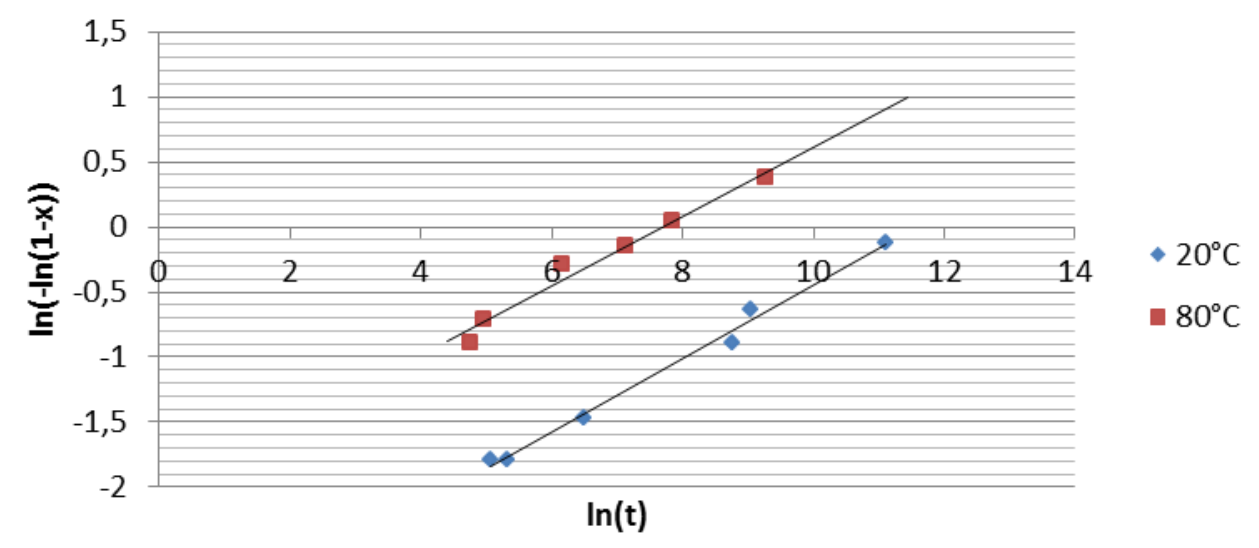

Fig.3. Representation of $\ln (-\ln (1-x))$ versus $\ln (t)$ on the softening transformation in overaging studied by isothermal hardness variations in the case of the crude casting alloy $\mathrm{Pb2 \%}$ Cd1\% Bi0,5\% Sn

Table.1. Coefficients of the equation of Johnson and Mehl-Avrami at different temperatures during over-aging in the case of the crude casting alloy $\mathrm{Pb2} \% \mathrm{Cd} 1 \% \mathrm{Bi0}, 5 \%$ Sn tempered in water.

\begin{tabular}{|c|c|c|}
\hline Temperature $\left({ }^{\circ} \mathbf{C}\right)$ & $\mathbf{n}$ & $\mathbf{k}\left(\mathbf{s}^{\mathbf{- 1}}\right)$ \\
\hline 20 & 0,281 & $9,055.10^{-6}$ \\
\hline 80 & 0,267 & $4,540.10^{-4}$ \\
\hline
\end{tabular}

From Table 1, we see that the values of $\mathbf{n}$ are almost the same for both temperatures. We can deduce that the reaction mechanism of the softening precipitation is simple.

\section{IV.3. Determination of the apparent activation energy:}

Assuming that $\mathrm{k}$ varies according to the Arrhenius law (Eq.6) from two coefficient values $\mathrm{k}$ of Johnson and Mehl-Avrami equation relating to temperatures $20^{\circ} \mathrm{C}$ and $80^{\circ} \mathrm{C}$ characterizing the kinetic of the transformation of over-aging in the case of the crude casting alloy $\mathrm{Pb} 2 \% \mathrm{Cd} 1 \%$ Bi0,5\%Sn; the equation (Eq.7) gives an apparent activation energy Q associated to this reaction approximate to $\mathbf{5 6 , 2 0 8 K j ~ / ~} \mathbf{m o l}$.

To verify that the activation energy does not depend on the degree of advancement, we will use the method of Burke [2] that calculates the activation energy without clarifying the function that represents the experimental curves. This method consists in measuring the $t_{x}$ time to reach a specified rate $\mathrm{x}$ of precipitation. Log $\mathrm{t}_{\mathrm{x}}$ values are plotted against $1 / \mathrm{T}$ in Figure (fig.4) for various values of $\mathrm{x}$. The slope of these lines remains practically constant with $\mathrm{x}$ and determines an apparent activation energy $Q$ which values are reported in Table 2 . These values are close to the value of the activation energy $56,208 \mathrm{Kj} / \mathrm{mol}$ given by the method of Burke [2]. 


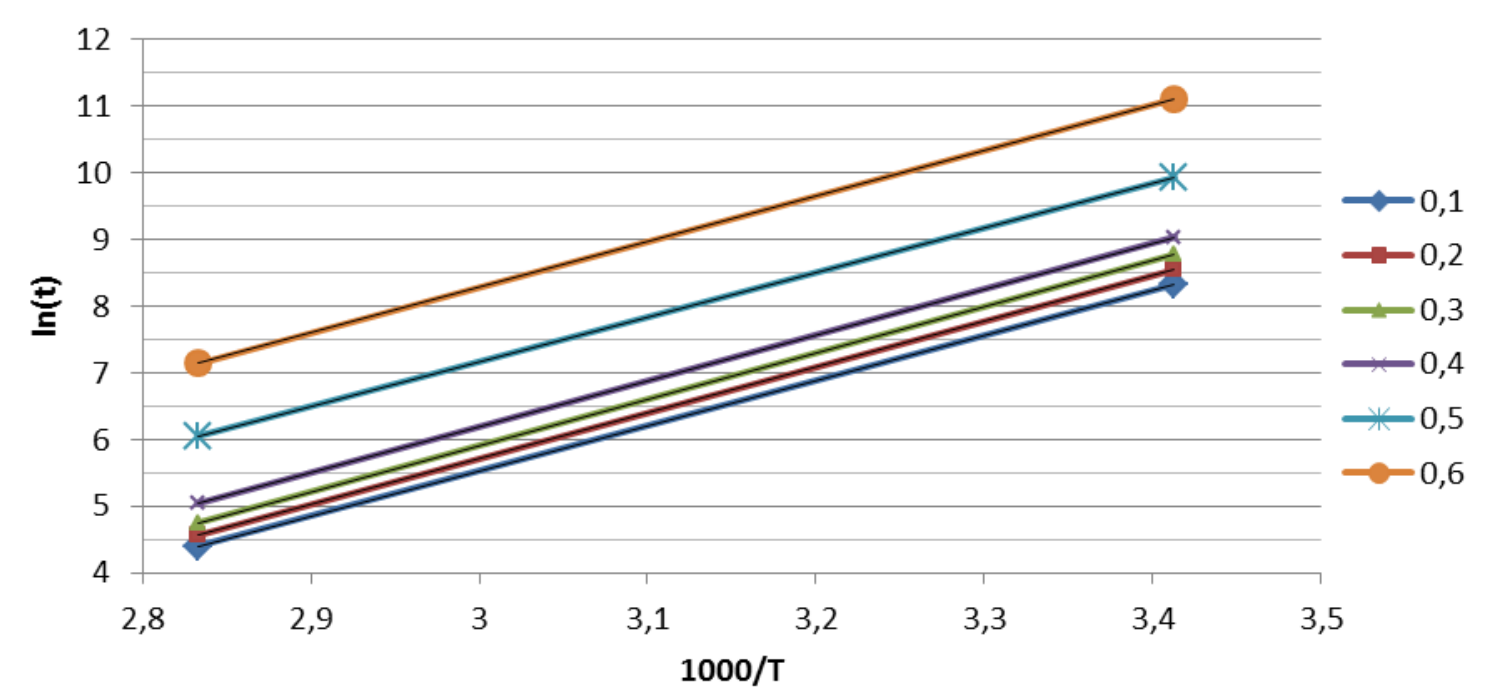

Fig.4. $\mathrm{Pb2} \% \mathrm{Cd} 1 \% \mathrm{Bi} 0,5 \% \mathrm{Sn}$ as cast alloy. Variation of $\log \mathrm{t}_{\mathrm{x}}$ as function of $1 / \mathrm{T}$

Table.2. Apparent activation energy values $Q$ for different rates of transformation in the case of as-cast alloy $\mathrm{Pb2} \% \mathrm{Cd} 1 \% \mathrm{Bi} 0,5 \%$ Sn soaked with water.

\begin{tabular}{|c|c|}
\hline Degree of advancement $\mathbf{x}$ & Apparent activation energy $\mathbf{Q}$ in (kJ/mol) \\
\hline 0,1 & 56,193 \\
0,2 & 57,092 \\
0,3 & 57,680 \\
0,4 & 57,240 \\
0,5 & 55,577 \\
0,6 & 56,930 \\
\hline
\end{tabular}

From Table 2, we see that the activation energy remains constant, it does not depend on the degree of advancement, and it's about $56.78 \mathrm{~kJ} / \mathbf{~ m o l}$.

\section{KINETIC STUDY OF THE ALLOY Pb2\%Cd1\%Bi2\%Mg:}

\section{V.1. degree of advancement of the reaction:}

Figure (fig.6) shows changes in the degree of advancement of the transformation $\mathrm{x}$ as a function of $\ln (\mathrm{t})$ for different temperatures $20^{\circ} \mathrm{C}$ and $80^{\circ} \mathrm{C}$. We obtain sigmoidal curves, elongated along the axis of time. The variations of degree of advancement at temperatures $20^{\circ} \mathrm{C}$ and $80^{\circ} \mathrm{C}$ are deduced from hardness measurements according to over-aging as shown in figure (fig.5) [4].

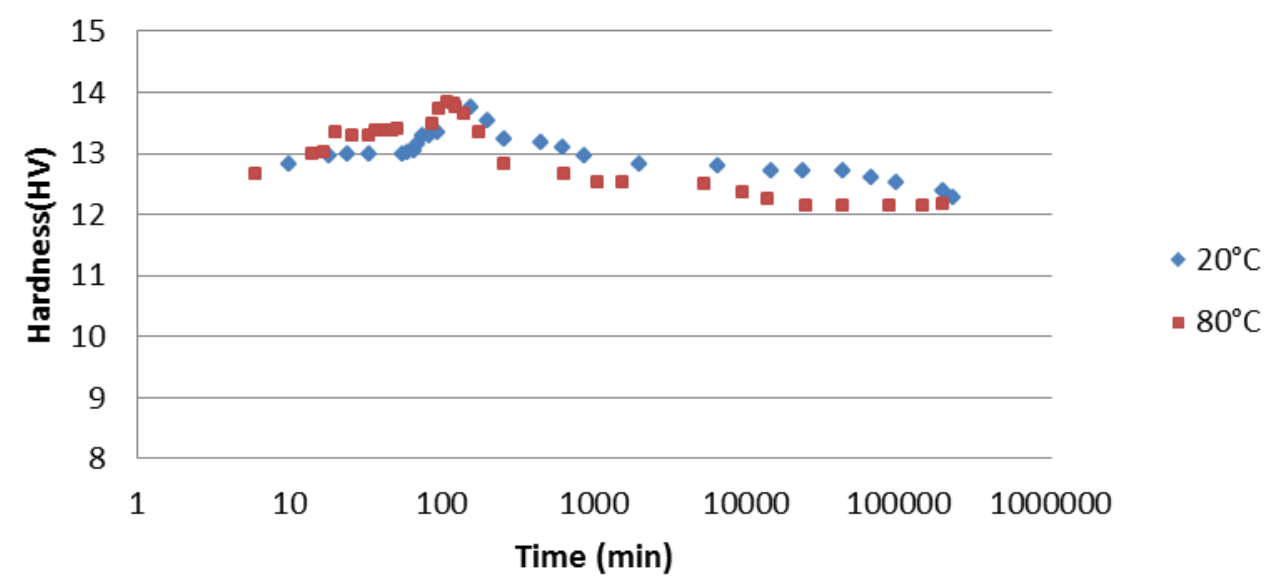

Fig.5. Evolution of the hardness of as cast alloy $\mathrm{Pb} 2 \% \mathrm{Cd} 1 \% \mathrm{Bi2} \% \mathrm{Mg}$ at temperatures $20^{\circ} \mathrm{C}$ and $80{ }^{\circ} \mathrm{C}$ as a function of time. 
We will take the maximum value of the curves of the evolution of the hardness versus time of Figure (fig.5), so $H V(0)=13,754 H \mathrm{~V}$. The final value of hardness for over-aging is reached since the last 6 month which is $H V(m)=12,285 H V$. The curves in Figure (fig.6), which are representative of the evolution of the discontinuous transformation, are deducted from hardness tests of Figure (fig.5) performed on raw casting samples maintained at $20^{\circ} \mathrm{C}$ and $80{ }^{\circ} \mathrm{C}$.

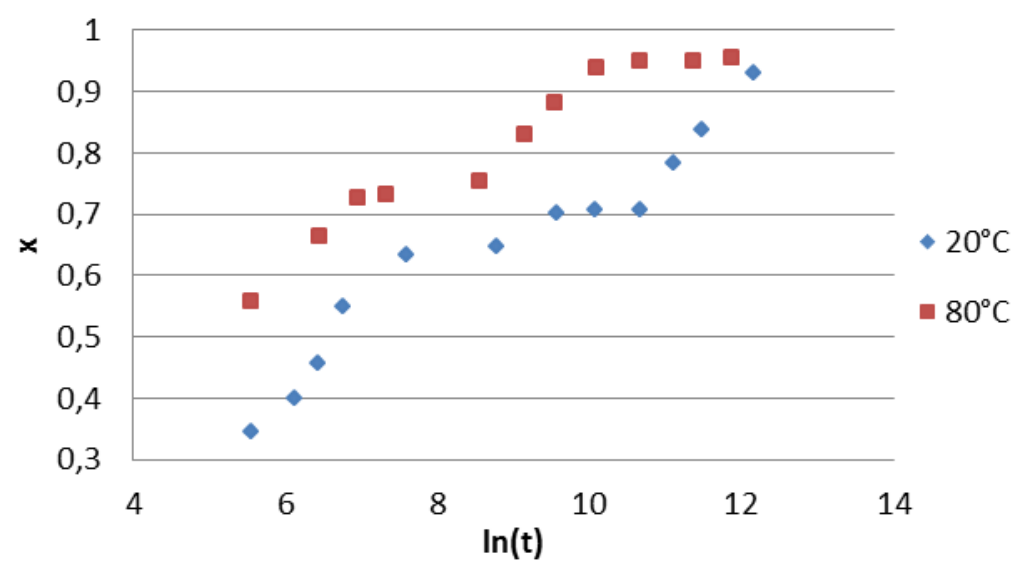

Fig.6. $\mathrm{Pb2} \% \mathrm{Cd} 1 \% \mathrm{Bi2} \% \mathrm{Mg}$ alloy. Transformed semi logarithmic of the curves of hardness tests at the temperatures $20^{\circ} \mathrm{C}$ and $80^{\circ} \mathrm{C}$ for softening discontinuous precipitation of the raw casting alloy tempered in water.

\section{V.2. Application of Johnson and Mehl-Avrami equation}

Figure (fig. 7) represents variations of $\log \log \left(\frac{1}{1-x}\right)$ as function of $\log (\mathrm{t}-\tau)$.

The start times of this transformation are respectively $154 \mathrm{~min}$ and $108 \mathrm{~min}$ for the temperatures $20^{\circ} \mathrm{C}$ and $80^{\circ} \mathrm{C}$. This figure shows that the points are placed on straight lines. The progress of this reaction is in conformity with Johnson and Mehl-Avrami equation [2].

Table 3 gives the values of the exponent $n$ calculated from the slope of the lines of Figure (fig.5) and the rate constants $\mathrm{k}$ for the different temperatures. The value of $\mathrm{n}$ is close to 0.22 for both temperatures.

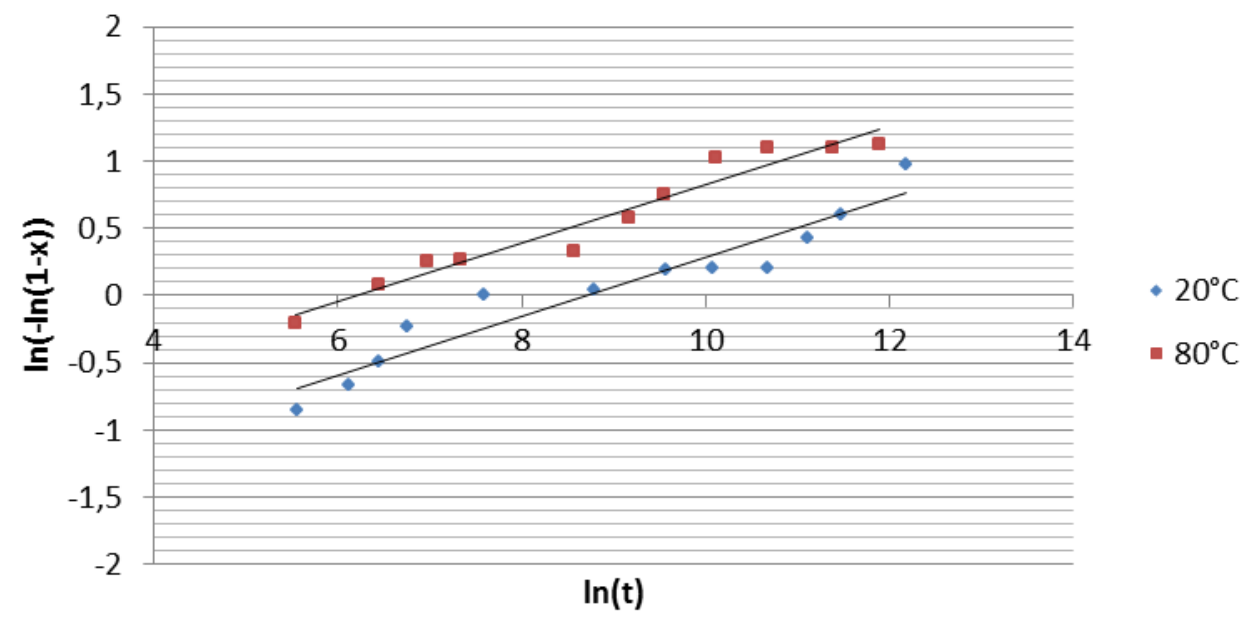

Fig.7. Representation of $\ln (-\ln (1-x))$ versus $\ln (t)$ on the softening transformation in overaging studied by isothermal hardness variations in the case of the crude casting alloy $\mathrm{Pb2} \% \mathrm{Cd} 1 \% \mathrm{Bi} 2 \% \mathrm{Mg}$ 
Table.3. Coefficients of the equation of Johnson and Mehl-Avrami at different temperatures during over-aging in the case of the crude casting alloy $\mathrm{Pb} 2 \% \mathrm{Cd} 1 \% \mathrm{Bi} 2 \% \mathrm{Mg}$ tempered in water.

\begin{tabular}{|c|c|c|}
\hline Temperature $\left({ }^{\circ} \mathbf{C}\right)$ & $\mathbf{n}$ & $\mathbf{k}\left(\mathbf{s}^{-1}\right)$ \\
\hline 20 & 0,219 & $1,608.10^{-4}$ \\
\hline 80 & 0,217 & $2,005.10^{-3}$ \\
\hline
\end{tabular}

From Table 3, we see that the values of $\mathbf{n}$ are almost the same for both temperatures. We can deduce that the reaction mechanism of the softening precipitation is simple.

\section{V.3. Determination of the apparent activation energy:}

Assuming that $\mathrm{k}$ varies according to the Arrhenius law (Eq.6) from two coefficient values $\mathrm{k}$ of Johnson and Mehl-Avrami equation relating to temperatures $20{ }^{\circ} \mathrm{C}$ and $80{ }^{\circ} \mathrm{C}$ characterizing the kinetic of the transformation of over-aging in the case of the crude casting alloy $\mathrm{Pb} 2 \% \mathrm{Cd} 1 \%$ $\mathrm{Bi} \% \mathrm{Mg}$; the equation (Eq.7) gives an apparent activation energy $\mathrm{Q}$ associated to this reaction approximate to $\mathbf{3 6 , 2 2 1 7} \mathbf{K j} / \mathbf{m o l}$.

To verify that the activation energy does not depend on the degree of advancement, we will use the method of Burke [2] that calculates the activation energy without clarifying the function that represents the experimental curves. This method consists in measuring the $t_{x}$ time to reach a specified rate $x$ of precipitation. Log $t_{x}$ values are plotted against 1/T in Figure (fig.8) for various values of $\mathrm{x}$. The slope of these lines remains practically constant with $\mathrm{x}$ and determines an apparent activation energy $Q$ which values are reported in Table 4 . These values are close to the value of the activation energy $36,2217 \mathrm{Kj} / \mathrm{mol}$ given by the method of Burke [2].

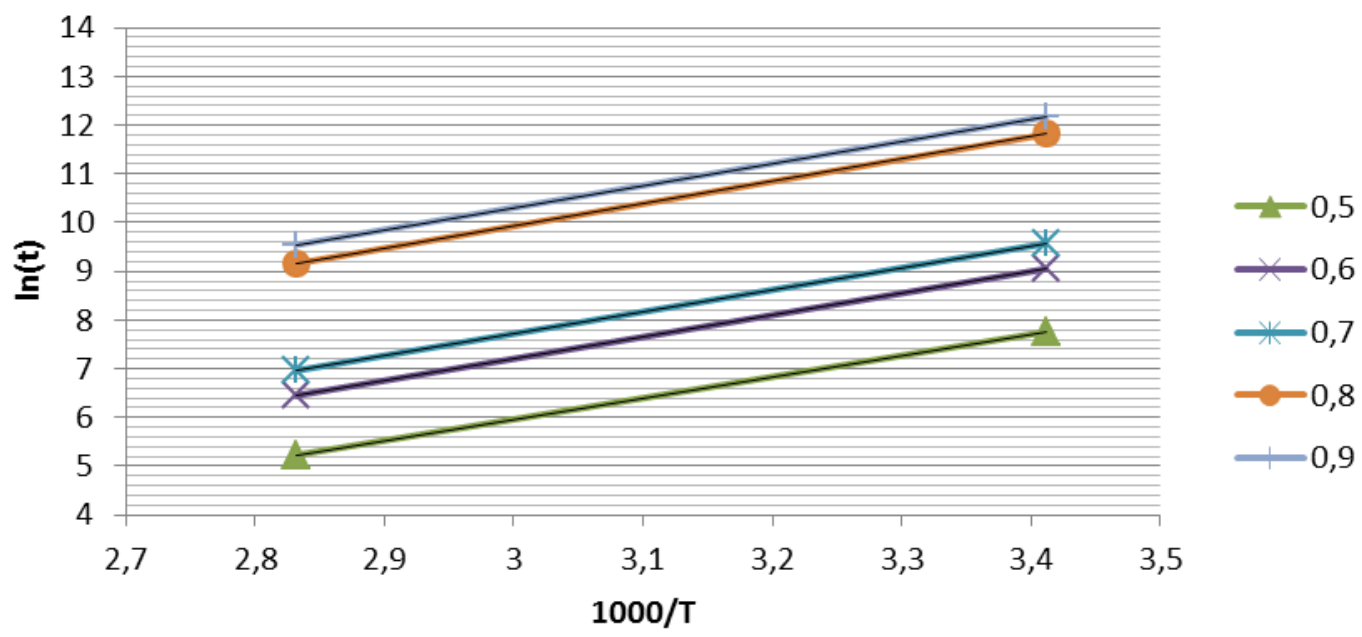

Fig.8. Pb2\%Cd1\%Bi2\%Mg as cast alloy. Variation of $\log t_{x}$ as function of 1/T

Table.4. Apparent activation energy values $Q$ for different rates of transformation in the case of as-cast alloy $\mathrm{Pb2} \% \mathrm{Cd} 1 \% \mathrm{Bi} 2 \% \mathrm{Mg}$ soaked with water.

\begin{tabular}{|c|c|}
\hline Degree of advancement $\mathbf{x}$ & Apparent activation energy $\mathbf{Q}$ en (kJ/mol) \\
\hline & \\
0,5 & 36,2752 \\
0,6 & 37,2819 \\
0,7 & 37,4732 \\
0,8 & 38,1056 \\
0,9 & 37,7395 \\
\hline
\end{tabular}

From Table 4, we see that the activation energy remains constant, it does not depend on the degree of advancement, and it's about $37,375 \mathrm{~kJ} / \mathbf{~ m o l}$. 


\section{VI-Conclusion :}

In this paper, we studied the kinetics of the alloys $\mathrm{Pb} 2 \% \mathrm{Cd} 1 \% \mathrm{Bi} 0,5 \% \mathrm{Sn}$ and $\mathrm{Pb} 2 \% \mathrm{Cd} 1 \% \mathrm{Bi} 2 \% \mathrm{Mg}$. We are interested especially in the kinetic study of over-aging to compare the activation energy of these alloys with $\mathrm{Pb} 2 \% \mathrm{Cd} 1 \% \mathrm{Bi}$ already studied. The increase of temperature has a slight influence on the hardness for both crude casting alloys $\mathrm{Pb} 2 \% \mathrm{Cd} 1 \% \mathrm{Bi} 0,5 \% \mathrm{Sn}$ and $\mathrm{Pb} 2 \% \mathrm{Cd} 1 \% \mathrm{Bi} 2 \% \mathrm{Mg}$.

Calculating the activation energy of the alloy $\mathrm{Pb} 2 \% \mathrm{Cd} 1 \% \mathrm{Bi} 2 \% \mathrm{Mg}$ shows the facility of the growth of the reaction during the over-aging by comparing it with the alloy $\mathrm{Pb} 2 \% \mathrm{Cd} 1 \% \mathrm{Bi} 0,5 \%$ $\mathrm{Sn}$. Indeed, the activation energy of the alloy $\mathrm{Pb} 2 \% \mathrm{Cd} 1 \% \mathrm{Bi} 2 \% \mathrm{Mg}$ is $36,22 \mathrm{Kj} / \mathrm{mol}$ and that of $\mathrm{Pb} 2 \% \mathrm{Cd} 1 \% \mathrm{Bi} 0,5 \% \mathrm{Sn}$ is $56,208 \mathrm{Kj} / \mathrm{mol}$, which means that the tin requires more energy for the growth of the reaction during over-aging.

The activation energy of the alloy without tin remains below the one with tin and approximate to that with $\mathrm{Mg}$ but both alloys studied in this paper have an activation energy remaining below that of lead which is $104 \mathrm{Kj} / \mathrm{mol}$.

The method of Burke support the values found by the method of JohsonMehl-Avrami since the activation energy is constant for the different degrees of advancement for alloys $\mathrm{Pb} 2 \% \mathrm{Cd} 1 \% \mathrm{Bi} 0,5 \% \mathrm{Sn}$ and $\mathrm{Pb} 2 \% \mathrm{Cd} 1 \% \mathrm{Bi} 2 \% \mathrm{Mg}$.

\section{References:}

[1] S.SAISSI et all, Journal of Science and Arts, 1(30),pp73-88, 2015.

[2] Burke,the kinetics of phases transformations in metals. Pergamon Press (1965).

[3] E. Jenkel and H. Hammes, Z. Metallkunde, 29 (1937) p89.

[4] S.SAISSI et all, Journal of Science and Arts, 4(29), pp331, 2014. 